\title{
Effects of vitamin $E$, selenium and vitamin $C$ on various biomarkers following oxidative stress caused by diazinon exposure in rainbow trout
}

\author{
Mohsen Ali ${ }^{\text {* }}$ - Alireza Mirvaghefi ${ }^{1}$ - Farzad Asadi2 \\ ${ }^{1}$ Department of Fisheries, Faculty of Natural Resources, University of Tehran, Karaj PO Box 4314, Iran \\ 2Department of Biochemistry, School of Veterinary Medicine, University of Tehran, Tehran, Iran \\ ${ }^{*}$ Corresponding Author: mani_a777@yahoo.com
}

\section{How to cite this paper:}

Ali, M., Mirvaghefi, A., Asadi, F., 2015 Effects of vitamin E, selenium and vitamin C on various biomarkers following oxidative stress caused by diazinon exposure in rainbow trout. Ege J Fish Aqua Sci 32(3): 151-158. doi: 10.12714/egejfas.2015.32.3.05

\begin{abstract}
Biochemical parameters are appropriate biomarkers to assess the effects of pesticides on an aquatic ecosystem. Diazinon is an organophosphate pesticide whose metabolism in fish body produces reactive oxygen species that can cause oxidative stress. In this study, Oncorhynchus mykiss were allocated into four treatment groups (with three replicates): control; Diazinon; vitamin C + diazinon, and vitamin E,selenium + diazinon. Blood samples were obtained after two and four weeks and superoxide dismutase (SOD), catalase (CAT), total antioxidant capacity (TAC), and malondialdehyde (MDA) were measured. SOD activity was significantly lower in diazinon-exposed fish than in the control group. However, there were no differences between the two supplemented groups and the control group in this regard. CAT activity was significantly higher in all three diazinon-exposed groups compared to the control group. However vitamin $\mathrm{E}$, selenium had the least difference with the control group. Maximum and minimum TAC were observed respectively in fish supplemented with vitamin E, selenium and those only exposed to diazinon. The diazinon group also had the highest MDA levels. The two supplemented groups and the control group had no significant differences in MDA levels. These findings highlighted the antioxidant effects of supplementation with vitamin $\mathrm{E}$, selenium or vitamin $\mathrm{C}$ against free radical produced during the metabolism of diazinon. Meanwhile, the combination of vitamin E, selenium had higher antioxidant effects than vitamin C. Moreover, SOD, the first defensive barrier against superoxide radicals, and MDA, an index of cellular damage induced by hydroxyl radicals, are the most suitable indicators to assess the effects of diazinon.
\end{abstract}

Keywords: Reactive oxygen species, oxidative stress, vitamin E, selenium, diazinon

\section{INTRODUCTION}

Diazinon, O, O-diethyl O-(2-isopropyl-6-methyl-4pyrimidinyl) phosphorothioate as defined by the International Union of Pure and Applied Chemistry (U.S.EPA, 2006), is an organophosphorus pesticide, used to control various insects in both agriculture and horticulture (Virtue and Clayton, 1997). It is available in different forms, e.g. powders, emulsions, and granules, and formulations. Diazinon has a half-life of about 30 39 days in waters of lakes and rivers (Arthur et al. 1983; Jarvinen and Tanner, 1982) and can be absorbed into the fish's body through the epithelial tissue of the gills, skin, and digestive system. After entering the blood, diazinon will be metabolized by liver cells (Vale, 1998).

Metabolism of diazinon in liver microsomes of rainbow trout (Oncorhynchus mykiss) produces hydroxypyrimidine, hydroxyl diazinon, and hydroxymethyl diazinon. These metabolites contain a hydroxyl agent which can easily transform to a strong free radical (Fujii and Asaka, 1982; Keizer et al. 1995). They also contain active polar groups such as $\mathrm{OH}$ - which can be disposed by participation in conjugated compounds. They may, on the other hand, turn into oxygen free radicals, e.g. hydroxyl and superoxide anion, which are capable of attacking and damaging cellular components (Fujii and Asaka, 1982). An obvious example of such damage is caused by the free radical chain reaction mechanism proceeding lipid peroxidation during which free radicals steal electrons from cell membranes (Pereira et al. 1995).

To overcome toxicological stress, fishes have various enzymatic defense mechanisms including the secretion of specific antioxidant defense enzymes, e.g. superoxide dismutase (SOD) and catalase (CAT), and formation of a cellular antioxidant defense system to scavenge free radicals (Halliwell and Gutteridge, 1990). SOD is the main defense factor against superoxide anion radicals and is in fact considered as the first line of defense against oxidative stresses. It accelerates the transformation of superoxide anions into molecular oxygen and hydrogen peroxide (Das et al. 1997; McCord and Fridovich, 1969). On the other hand, CAT, which is found in cells of aerobic organisms, decomposes hydrogen peroxide to water and oxygen (Aebi, 1984).

Moreover, non-enzymatic antioxidant defense mechanisms involve various chemical groups such as vitamins, carotenoids, amino acids, and peptides (Zama et al. 2007). Vitamin E is a fat-soluble vitamin with antioxidant properties. It prevents lipid peroxidation and protects cell membranes by establishing a 
structure against primarily peroxyl radicals (ROO) (Di Giulio and Meyer, 2008). In addition to vitamins, selenium can play a major role in the removal of free radicals. As glutathione peroxidase (GPX), a selenium-containing enzyme, contributes to the decomposition of hydrogen peroxide (Bell et al. 1986), selenium can be regarded as a micronutrient that indirectly protects the cells of an organism from serious damages caused by the presence of hydrogen peroxide (Bell et al. 1986). Therefore, dietary supplementation with a combination of vitamin $\mathrm{E}$ and selenium may protect cell membranes against lipid oxidation (Bell et al. 1985; Bell et al. 1987) and exert synergistic effect in hydroperoxide detoxification (Bell et al. 1985).

Another non-enzymatic antioxidant is vitamin C (ascorbic acid). Since most bony fishes lack $L$ gulonolactone oxidase to convert glucose and are thus unable to synthesize vitamin C, they need to receive this vitamin from food (Moreau et al. 1999; Verlhac and Gabaudan, 1997). Intake of adequate vitamin C by rainbow trout can neutralize the revival of $\mathrm{O}_{2-}, \mathrm{OH}$, and $\mathrm{H}_{2} \mathrm{O}_{2}$ free radicals and prevent the damages caused by oxidative stresses (Verlhac and Gabaudan, 1997; Verlhac et al. 1998). All these antioxidant factors present in the body of an organism, either intracellular enzymes or antioxidant nutritional compounds (non-enzymatic factors), are called its total antioxidant capacity (TAC) (Mahfouz et al. 2009). In other words, TAC shows how capable an organism is in removing free radicals (Miller et al. 1993).

Physiological and biological changes in the bodies of various organisms, especially the fish, are appropriate biomarkers for the evaluation of environmental contaminants and environmental health of aquatic ecosystems. Such biomarkers are considered as warning signals received from living organisms to acquaint humans with the hazards of different environmental pollutants (Payne et al. 1987). Biomarkers are defined as changes in biological responses of an organism (at cellular, molecular, biochemical, and physiological levels) after exposure to toxins or chemicals in the natural environment (Van der Oost et al. 2003).

Understanding biochemical mechanisms, including antioxidant defense, involved in detoxification processes can help elucidate the required biomarkers to evaluate the damaging effects of various environmental pollutants in aquatic systems. For instance, SOD and CAT are the first line defense against reactive oxygen species (ROS). Cheung et al. assessed the suitability of numerous antioxidant parameters such as SOD, CAT, GPX, glutathione-S-transferase (GST), and glutathione reductase (GR) as biomarkers in various organisms (Cheung et al. 2001). Moreover, malondialdehyde (MDA), the end product of lipid peroxidation, is directly related to cell damage during oxidative stress and can be used in evaluation of such damages (Doba et al. 1985).

According to previous studies, the optimal levels of selenium, vitamin $E$, and vitamin $\mathrm{c}$ in the diet of rainbow trout are $0.15-0.40 \mathrm{mg} / \mathrm{kg}$ (Hillton et al. 1980), $100 \mathrm{mg} / \mathrm{kg}$ (Watanabe et al. 1981), and $300 \mathrm{mg} / \mathrm{kg}$ (Verlhac et al. 1998), respectively. The present study measured SOD and CAT activities, TAC, and serum levels of MDA to illuminate the antioxidant effects of dietary vitamin $\mathrm{E}$, selenium, and vitamin $\mathrm{C}$ in the rainbow trout exposed to subacute dosages of diazinon.

\section{MATERIALS AND METHODS}

This was an in vivo study with ecotoxicological assessment.

\section{Experimental Animals}

A total of 180 immature rainbow trouts (mean weight: 121 $\pm 18 \mathrm{~g}$, mean length: $22.9 \pm 1.6 \mathrm{~cm}$ ) were purchased from a fish farm in Karaj, Iran $\left(35^{\circ} 49^{\prime} \mathrm{N} / 51^{\circ} 1^{\prime} \mathrm{E}\right)$. The fish were transferred from a $1000 \mathrm{~L}$ tank into four $300 \mathrm{~L}$ fiberglass tanks filled with farm water and aerated with oxygen cylinders. A period of seven days was considered for fish adaptation. During the whole experiment, $10 \%$ of the total volume of tank water was changed per day. The mean temperature, $\mathrm{pH}$, dissolved oxygen, and water hardness during the experiment period were $12.5 \pm 1.0^{\circ} \mathrm{C}, 7.8 \pm 0.1,8.0 \pm 0.5 \mathrm{mg} / \mathrm{L}$, and $205 \pm 16(\mathrm{mg} / \mathrm{L}$ $\mathrm{CaC}_{3}$ ), respectively. The fish were divided into four groups of 15 with three replicates. While the control group remained in unpolluted water, the other groups were exposed to $0.1 \mathrm{mg} / \mathrm{L}$ diazinon. One group was then maintained untreated while the other two received either vitamine $\mathrm{C}(300 \mathrm{mg} / \mathrm{kg})$ or vitamin $\mathrm{E}$ $(100 \mathrm{mg} / \mathrm{kg})$ plus selenium $(0.5 \mathrm{mg} / \mathrm{kg})$. The groups and received a diet equal to $2 \%$ of their body weight and were studied for four weeks.

\section{Chemical Materials and Equipment}

Diazinon emulsion (60\%) and soluble diazinon (40\%) were purchased from Partovnar Co., Iran. In order to produce subacute composition of diazinon $(0.1 \mathrm{mg} / \mathrm{L})$, the stock solution of 10 parts per trillion (ppt), i.e. 0.1 of its sub-lethal concentration (Eisler, 1998), was produced (Koprucu et al. 2006). Encapsulated L-ascorbic acid-2-phosphate, a form of vitamin $\mathrm{C}$ which is stable in water, was also bought (Tiger $\mathrm{Co}$., China). The chemical formula and molecular weight of vitamin C were $\mathrm{C}_{6} \mathrm{H}_{9} \mathrm{O}_{9} \mathrm{P}$ and $256.11 \mathrm{~g} / \mathrm{mol}$, respectively. A solution containing $100,000 \mathrm{mg} / \mathrm{L}$ vitamin $\mathrm{E}$ and $500 \mathrm{mg} / \mathrm{L}$ selenium (sodium selenite) was also prepared (Damloran pharmaceutical Co., Iran).

\section{Preparation of Serum Samples}

Sampling was performed at the end of the second and fourth weeks. A clover powder solution of 100 parts per million (ppm) was used to anesthetize the fish during blood sampling. Blood samples were obtained from the hemal arch in the caudal peduncle using $2 \mathrm{~mL}$ syringes (without heparin as an anticoagulant). Five fish from each tank were randomly selected at each sampling time. The samples were transferred into $2 \mathrm{cc}$ tubes (Eppendorf International, Germany) and centrifuged at 4500 rounds per minute (rpm) for 15 minutes. The isolated serums were then maintained in a freezer at $-70^{\circ} \mathrm{C}$ until analysis. 


\section{SOD Measurement}

The method suggested by Marklund and Marklund (1974), was applied to assess SOD levels in serum samples. The mentioned method measured SOD activity based on the oxidation of pyrogallol in the presence of hydrogen peroxide. Since serum levels of SOD in serum determine the reduction in pyrogallol oxidation, decreased absorption of light $(420 \mathrm{~nm})$ in spectrophotometry was measured. One unit of SOD activity was defined as the amount of enzyme which causes 50\% inhibition of pyrogallol autoxidation.

\section{CAT Measurement}

CAT activity was assessed according to the method proposed by Goth (1991). At first, serum samples and hydrogen peroxide solution were mixed and maintained at room temperature for 10 minutes. Ammonium molybdate was then used to stop the oxidation process and determine the CAT activity. Goth demonstrated that higher CAT activity in serum was associated with less light absorption at $410 \mathrm{~nm}$. Therefore, each unit of enzyme activity was defined as enzyme activity which could decompose $1 \mathrm{~mm}$ of hydrogen peroxide in one second.

\section{TAC Measurement}

Ferric-reducing ability of plasma (FRAP) assay, proposed by Koracevic et al. (2001), was used to examine TAC. Accordingly, a standard solution of complex ferricethylenediaminetetraacetic acid (Fe-EDTA) and hydrogen peroxide produced hydroxyl radicals during Fenton reaction. The resulting reactive oxygen then caused thiobarbituric acid (TBA), a reactive acid, to be released. In this method, according to total antioxidant serum samples studied, the production of TBA was inhibited. Absorption at wavelength of $532 \mathrm{~nm}$ will then be reduced as a result of decreased color production.

\section{Lipid Peroxidation Measurement Using MDA}

The method suggested by Ledwozyw et al. (1986), was employed to assess MDA. Hence, $1 \mathrm{ml}$ of the obtained serum samples was mixed with $2 \mathrm{ml}$ trichloroacetic acid, TBA, and hydrochloric acid under acidic conditions. The mixture was then diluted to $200 \mathrm{ml}$ with distilled water and settled in a sudatorium for 30 minutes. Afterward, the tubes were transferred in vitro to be cooled. Later, the samples were centrifuged for at $300 \mathrm{rpm}$ for 10 minutes and the supernatant solution was carefully isolated. The absorption rate at $535 \mathrm{~nm}$ was finally calculated. As the level of absorption depended on TBA inhibition by MDA in the serum, higher MDA levels caused greater TBA inhibition and less color production (absorption).

\section{Statistical Analysis}

One-way analysis of variance (ANOVA) and Tukey's tests were applied to analyze the collected data. All analyses were performed in SPSS for Windows 16.0 (SPSS Inc., Chicago, IL, USA) at a significance level of $P<0.05)$. Bar graphs were also drawn in Microsoft Excel 2007 to depict the mean \pm standard deviation (SD).

\section{Theory}

Biotransformation of xenobiotic compounds in fish liver requires three major phases as follows:

The first phase involves oxidation-chemical reduction and hydrolysis processes and is controlled by microsomal monooxygenase such as cytochrome P450. During the second phase, the resulting metabolites will become water soluble through exposure to a new set of enzymes. They will thus be able to easily exit the cell walls and be completely excreted from the aquatic organism. At this stage, some harmful compounds, i.e. ROS, can damage cells by interacting with vital intracellular molecules.

Despite the various enzymatic antioxidant defense mechanisms, cells have a limited capacity for enzyme production. Therefore, exposure to acute or subacute doses of pollutants will definitely threaten aquatic organisms. In order to deal with such threats, several non-enzymatic antioxidant compounds such as vitamins, carotenoids (e.g. beta-carotene), amino acids, and peptides have also been identified. As these compounds can prevent the formation of free radicals and inhibit their activity through averting their binding to cell membranes and compounds, they are believed to help living organisms reach hemostasis.

Research aiming to model the biochemical mechanisms between intracellular antioxidant enzymes and non-enzymatic antioxidant compounds (as scavengers) can be beneficial in clarification of the overall oxidative defense mechanisms against ROS. Moreover, measurement of enzymes other than those described in the current study (e.g. glutathione, GPX, and glucose-6-phosphate dehydrogenase) can expand the existing knowledge about the cellular antioxidant defense system against ROS.

\section{RESULTS}

\section{Evaluation of SOD Activity}

The results of ANOVA for SOD levels in the second and fourth weeks were $F 3,16=9.707 ; P=0.001$ and $F 3,16=$ 36.193; $P<0.001$, respectively.

Untreated fish exposed to diazinon had significantly lower SOD levels compared to the control group $(P<0.001)$. No significant difference in SOD level was detected between the unsupplemented fish exposed to diazinon and those supplemented with vitamin $C(P=0.117)$. The SOD activity levels in fish exposed to diazinon and treated with vitamin $E$ plus selenium did not have a significant difference with the levels in the control group $(P=0.299)$. However, SOD increased significantly in the specimens treated with vitamin $\mathrm{E}$ plus selenium compared to the untreated diazinon-exposed group $(P=0.016)$. On the other hand, after four weeks, SOD decreased significantly in the group exposed to diazinon compared to the other groups. Meanwhile, the three groups were not significantly different in this regard (Figure 1). 


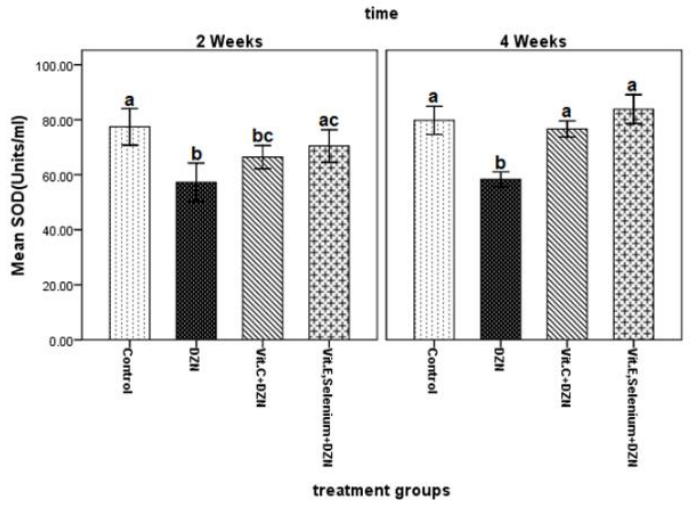

Figure1. Changes in superoxide dismutase (SOD) activity levels in serum samples of fish exposed to diazinon $(0.1 \mathrm{mg} / \mathrm{L})$ and treated with either vitamin $\mathrm{E}$, selenium or vitamin $\mathrm{C}$ compared to the control group after two and four weeks. Five fish in each group were sampled. Different alphabetic letters $(a, b$ $c, d)$ show significant differences $(P<0.05)$ and similar alphabetic letters show lack of a significant difference between groups (DZN: diazinon; Vit: vitamin)

\section{Evaluation of CAT Activity}

The results of ANOVA regarding CAT levels in the second and fourth weeks were $\mathrm{F} 3,16=81.871 ; \mathrm{P}<0.001$ and $\mathrm{F} 3,16=$ $65.575 ; P<0.001$, respectively.

At the end of the second and fourth weeks, CAT activity was significantly higher in fish exposed to diazinon than in the control group $(P<0.001)$ (Figure 2). CAT levels in fish treated with vitamin $C$ increased significantly compared to the control group $(P<0.001)$. On the other hand, there was no significant difference between the untreated diazinon-exposed group and vitamin $\mathrm{C}$ supplemented fish in two stages of sampling (Figure 2). Meanwhile, the group supplemented with vitamin $E$ plus selenium had significantly lower CAT levels compared to vitamin $\mathrm{C}$-treated and untreated fish exposed to diazinon $(\mathrm{P}<$ 0.001) (Figure 2)

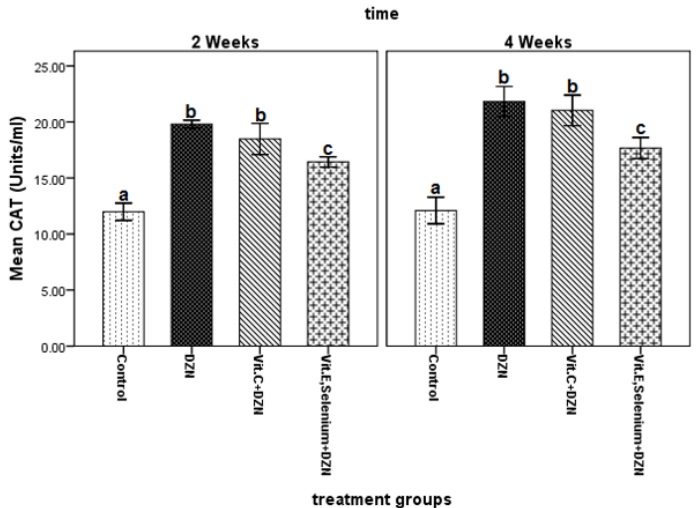

Figure 2. Changes in catalase (CAT) activity levels in serum samples of fish exposed to diazinon $(0.1 \mathrm{mg} / \mathrm{L})$ and treated with either vitamin $\mathrm{E}$,selenium or vitamin $\mathrm{C}$ compared to the control group after two and four weeks. Five fish in each group were sampled. Different alphabetic letters (a, b, c, d) show significant differences $(P<0.05)$ and similar alphabetic letters show lack of a significant difference between groups (DZN: diazinon; Vit: vitamin)

\section{Evaluation of TAC}

The results of ANOVA for TAC levels in the second and fourth weeks were F3,16 $=256.638, P<0.001$ and $F 3,16=$ $17.826, P<0.001$, respectively.

At the end of the second and fourth weeks, fish exposed to diazinon had significantly lower TAC compared to the control group (P2weeks < 0.001; P4weeks = 0.033) (Figure 3). Two weeks of vitamin $C$ supplementation significantly increased $(P$ $<0.001)$ TAC in comparison with the untreated, diazinonexposed and control groups. However, this difference did not remain significant $(P=0.055)$ at the end of the fourth week. On the other hand, among all groups, diazinon-exposed fish supplemented with vitamin $E$ plus selenium had the highest TAC at the end of the second and fourth weeks $(P<0.001)$ (Figure 3).

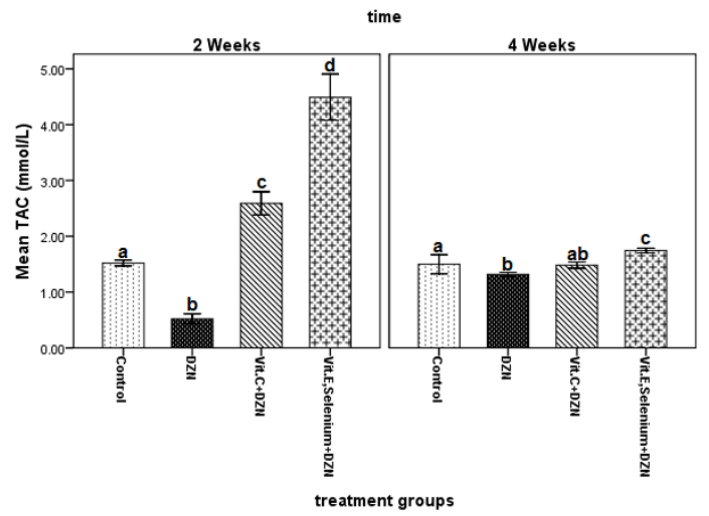

Figure 3. Changes in total antioxidant (TAC) activity levels in serum samples of fish exposed to diazinon $(0.1 \mathrm{mg} / \mathrm{L})$ and treated with either vitamin E,selenium or vitamin C compared to the control group after two and four weeks. Five fish in each group were sampled. Different alphabetic letters $(a, b$, $c, d)$ show significant differences $(P<0.05)$ and similar alphabetic letters show lack of a significant difference between groups (DZN: diazinon; Vit: vitamin)

\section{Evaluation of MDA levels}

The results of ANOVA for MDA levels in the second and fourth weeks were $F 3,16=18.029 ; P<0.001$ and $F 3,16=$ 29.781; $P<0.001$, respectively.

At the end of the second and fourth weeks, the diazinonexposed fish had significantly higher MDA levels compared to the control group $(P<0.001)$ (Figure 4). MDA levels in the fish fed with vitamin $C$ were significantly higher than that in the control group only at the end of the second week $(P=0.016)$. No such a difference was detected after four weeks $(P=0.427)$. However, supplementation with vitamin $E$ plus selenium prevented cellular destruction caused by diazinon exposure and maintained MDA levels close to the levels in the control group $($ P2weeks $=0.797 ; \mathrm{P}$ 4weeks $=0.990)($ Figure 4). 


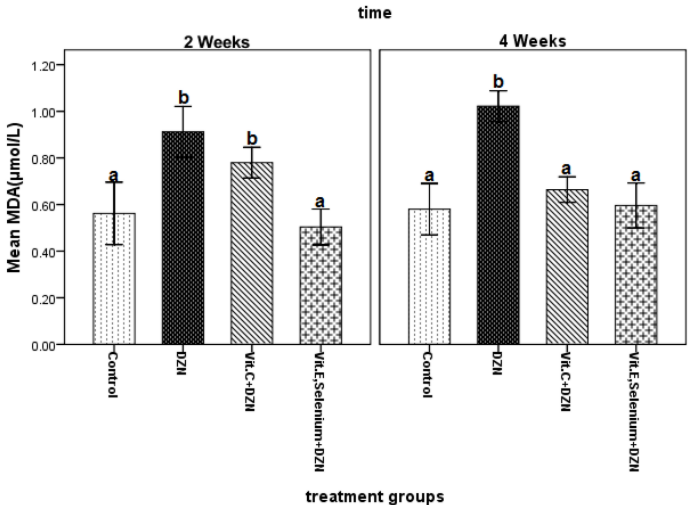

Figure 4. Changes in malondialdehyde (MDA) activity levels in serum samples of fish exposed to diazinon $(0.1 \mathrm{mg} / \mathrm{L})$ and treated with either vitamin E,selenium or vitamin $\mathrm{C}$ compared to the control group after two and four weeks. Five fish in each group were sampled. Different alphabetic letters $(a, b$ $c, d)$ show significant differences $(P<0.05)$ and similar alphabetic letters show lack of a significant difference between groups (DZN: diazinon; Vit: vitamin)

\section{DISCUSSION}

The present study evaluated the activity of antioxidant enzymes and lipid peroxidation during oxidative stress in rainbow trout. In fact, we exposed the fish to diazinon and assessed the efficacy of vitamin $C$ and vitamin $E$ plus selenium in reducing its adverse effects. The results obtained after two and four weeks suggested that exposure to $0.1 \mathrm{ppm}$ diazinon could decrease SOD levels in rainbow trout. Increased volume of superoxide anion radicals $\left(\mathrm{O}_{2 .-}\right)$ after the metabolism of diazinon might have been responsible for this finding. A previous study justified decreased SOD levels in rainbow trout 24,48 , and 72 hours after exposure to $0.5-1.0 \mathrm{ppm}$ diazinon by the depletion of the enzyme following the removal of superoxide anion radicals (Isik and Celik, 2008).

Moreover, increased CAT levels were observed in the untreated diazinon-exposed fish after both two and four weeks. This finding indicated the elevated amounts of hydrogen peroxide $\left(\mathrm{H}_{2} \mathrm{O}_{2}\right)$ as a result of $\mathrm{SOD}$ activity. Research has shown 40 days of exposure to atrazine and chlorpyrifos to raise CAT activity in the liver tissues and gills of the Cyprinus carpio. As mentioned, higher levels of superoxide anion radicals following the exposure trigger the greater production of the enzyme (Xing et al. 2012). It can thus be argued that certain types of diazinon metabolism caused by the production of oxygen free radicals can ultimately lead to decreased SOD levels and increased CAT levels.

In the current study, TAC of diazinon-exposed fish was significantly lower than that of the control group at both sampling times. This reduction in antioxidant capacity occurred due to the process of cleaning and scavenging of free radicals by enzymatic and non-enzymatic antioxidant defense systems. A previous study indicated that subacute diazinon affected liver hepatocytes in rainbow trout and resulted in decreased TAC. The researchers introduced excessive production of free radicals during the metabolism of diazinon in the liver (the detoxification process) as the main reason for this finding
(Banaee et al. 2011). Monterio et al. (2006), reported oxidative processes which increased ROS to contribute to reduced TAC.

Lipid peroxidation evaluations in the present research showed that after two and four weeks, MDA levels were significantly higher in the untreated diazinon-exposed group than in the control group. Such increments reflect the higher production of hydroxyl radicals $(\mathrm{OH}-)$ subsequent to exposure to the poison. Hydroxyl radicals are oxidizers with a key role in the initiation of lipid oxidation processes. Increased MDA levels were also confirmed in a study on the effects of 15 and 30 days of exposure to $0.1 \mathrm{mg}$ diazinon on muscle tissues and kidneys of Oreochromis niloticus (Durmaz et al. 2006). In general, decomposition of diazinon can generate oxygen free radicals, such as superoxide anion radical and strong hydroxyl ions, which in turn raise MDA levels. This increase may be due to the decomposition membrane lipids during exposure to the mentioned toxic metabolites (Hazarika et al. 2003; Valavanidis et al. 2006).

We could not establish significant differences between SOD levels of the control group and the diazinon-exposed fish supplemented with vitamin $E$ plus selenium at any time. Likewise, SOD levels of the control group and the fish fed with vitamin $\mathrm{C}$ were not significantly different at the end of the fourth week. In the present study, SOD levels in the control group and the groups supplemented with either vitamine $C$ (after four weeks) or vitamin $E$ plus selenium (during the whole study) were not significantly different. This finding can be justified by antioxidant activity of the supplements (especially vitamin $E$ plus selenium) against superoxide anion radicals produced during the metabolism of diazinon. Such an activity mimics the effects of SOD and prevents its depletion following diazinon exposure.

Adding vitamin $E$ to the diet of African catfish (Clarias gariepinus) with long-term exposure to atrazine resulted in decreased SOD levels in the liver tissue. This highlights the similar function of vitamin $E$ and $S O D$ in decreasing free radicals (Kadry et al. 2012). Vitamin C, on the other hand, can lose one electron and reduce ROS. It can also modulate the antioxidant enzyme levels (Sies and Stahl, 1995).

CAT levels in fish treated with vitamin $E$ plus selenium were significantly lower than other groups at the end of the second and fourth weeks. This can be justified by the antioxidant activity of these nutrients in the decomposition of hydrogen peroxide (which is parallel to CAT activity). GPX is an important selenium-containing antioxidant enzyme which acts similar to CAT in neutralizing free radicals.

On the other hand, two and fourweek treatment of diazinonexposed fish with vitamin $\mathrm{C}$ was associated with significant increments in CAT levels (similar to untreated diazinon fish). The difference remained significant at the end of both the second and fourth weeks. This increase is probably due to the inability of vitamin $\mathrm{C}$ to degrade hydrogen peroxide, i.e. the increase in CAT level indicates increased amounts of hydrogen peroxide during the intracellular detoxification 
process.

A similar study using an antioxidant compound called silymarin reported reduced CAT levels in rainbow trout exposed to diazinon. The authors explained their finding by the secretion of diazinon metabolites in presence of silymarin (Banaee et al. 2011). We found comparable results in the group supplemented with vitamin $E$ and selenium. However, introducing lycopene, a carotenoid and antioxidant, to the diet of Cyprinus carpio exposed to chlorpyrifos (an organophosphorus pesticide) could increase CAT levels (Ural, 2013). Therefore, the effects of lycopene and vitamin C are similar.

We also detected the diazinonexposed fish treated with vitamin $E$ plus selenium to have significantly higher TAC compared to other groups. This finding reflects the higher antioxidant capacity of this combination in comparison with vitamin $C$. In addition, adding vitamin $C$ to the diet of the diazinon-exposed fish significantly increased TAC levels compared to the untreated diazinon-exposed fish and the control group.

Vitamin E, ascorbic acid (vitamin C), uric acid, and glutathione comprise about $70 \%$ of the total antioxidant activity. Winston et al. suggested vitamins $E$ and $C$ to make up a great share of the TAC (Winston and Di Giulio, 1991). Research has also revealed the association between increased TAC and enhanced ability of an organism to neutralize and remove free radicals (Karaoz et al. 2002). As vitamin $E$ and selenium are critical components of the antioxidant defense and major determinants of TAC, the highest levels of TAC in fish supplemented with these two nutrients in the present study seem logical.

In the current study, MDA levels in the fish supplemented with vitamin $E$ plus selenium and the control group were not significantly different. However, adding vitamin $\mathrm{C}$ to the diet of diazinon-exposed fish significantly increased MDA levels (compared to the control group) at the end of the second week. Nevertheless, such a difference was not present at the end of the fourth week. According to available literature, vitamin $\mathrm{E}$ is a strong antioxidant which can prevent lipid peroxidation caused by the formation of lipid hydroperoxides (Bell et al. 1985). Selenium is also an important part of GPX and is responsible for reducing oxygen free radicals and interrupt lipid oxidation

\section{REFERENCES}

Aebi, H., 1984. "Catalase in vitro." Methods Enzymol, 105: 121-126. doi:10.1016/s0076-6879(84)05016-3

Arthur, J.W., Zischke, J.A., Allen, K.N., Hermanutz, R.O., 1983. Effects of diazinon on macroinvertebrates and insect emergence in outdoor experimental channels. Aquat Toxicol, 4(4): 283-301. doi:10.1016/0166-445x(83)90023-1

Banaee, M., Sureda, A., Mirvaghefi, A.R., Ahmadi, K., 2011. Effects of diazinon on biochemical parameters of blood in rainbow trout (Oncorhynchus mykiss). Pesticide Biochemistry and Physiology 99 (1): 1-6. doi:10.1016/pestbp.2010.09.001
(Rotruck et al. 1973). Using dietary vitamin E reduced lipid peroxidation in liver tissues of female African catfish (Clarias gariepinus) dealing with chronic atrazine exposure (Kadry et al. 2012).

Among all measured biochemical factors, SOD is the first specific antioxidant defense barrier against superoxide anion radicals. In addition, it is more sensitive than CAT to exposure to diazinon. Therefore, SOD seems an appropriate biomarker for monitoring aquatic ecosystems.

While evaluating total antioxidant levels is crucial to the general investigation of oxidative events in a biological system, the interpretation of changes in biochemical factors in complex ecological levels is difficult due to several factors. MDA is an indicator of lipid peroxidation (caused by the exposure of cell membranes to free hydroxyl radicals produced during the metabolism of diazinon). As it reflects the level of damage in aquatic organisms, it has been suggested as a reliable biomarker to assess the effects of environmental pollutants (Valavanidis et al. 2006; Van der Oost R et al. 2003).

Considering the possible presence of diazinon in aquatic ecosystems and its damaging effects, the use of vitamin $E$ and selenium can be enhance non-enzymatic antioxidant defense and adjust the levels of SOD and CAT to their normal values. Such an intervention can also increase TAC in fish.

MDA measurements in the present study showed the efficacy of vitamin $E$ and selenium in preventing lipid peroxidation. Vitamin $C$ was also partially beneficial in the adjustment of SOD activities. Moreover, vitamin $C$ was less effective than vitamin $E$ plus selenium in improving TAC and inhibiting lipid peroxidation.

In conclusion, our study demonstrated that introducing a combination of vitamin $\mathrm{E}$ and selenium into the diet of rainbow trout, especially during the agriculture farming season when the presence of diazinon in waters is more probable, could enhance the fish's antioxidantdefense.

\section{ACKNOWLEDGEMENT}

The present study was conducted using the equipment available in the Faculty of Natural Resources of Tehran University (Iran). We wish to acknowledge all those who supported us in conducting this research.

Bell, J.G., Adron, J.W., Cowey, C.B., 1986. Effect of selenium deficiency on hydroperoxide stimulated release of glutathione from isolated perfused liver of rainbow trout (Salmo gairdneri). $\mathrm{Br} J$ Nutr 56 (2): 421-428. doi:10.1079/BJN19860122

Bell, J.G., Cowey, C.B., Adron, J.W., Pirie, B.J.S., 1987. Some effects of selenium deficiency on enzyme activities and indices of tissue peroxidation in Atlantic salmon parr (Salmo salar). Aquaculture 65 (1): $43-$ 54. doi: 10.1016/0044-8486(87)90269-9

Bell, J.G., Cowey, C.B., Adron, J.W., Shanks, A.M., 1985. Some effect of vitamin $E$ and selenium deprivation on tissue enzyme levels and indices 
of tissue peroxidaion in rainbow trout (Salmo gairdneri). Br J Nutr 53 (1) 149-157. doi:10.1079/BJN19850019

Cheung, C.C.C., Zheng, G.S., Li, A.M.Y., Richardson, B.J., Lam, P.K.S., 2001 Relationship between tissue concentrations of Polycyclic Hydrocarbons and antioxidative responses of marine mussels, Perna viridis. Aquat Toxicol 52 (3-4): 189-203 doi:10.1016/S0166-445X(00)00145-4

Das, K.C., Lewis-Molock, Y., White, C.W., 1997. Elevation of manganese superoxide dismutase gene expression by thioredoxin. Am J Respir Cell Mol Biol 17 (6): 713-726. doi:10.1165.ajrcmb.17.6.2809

Di Giulio, R. T., Meyer, J.N., 2008. Reactive oxygen species and oxidative stress. In The Toxicology of Fishes, edited by Di Giulio, R. T., and D. E. Hinton, 273-324. FL: CRC Press, Boca Raton.

Doba, T., Burton, G.W., Ingold, K.U., 1985. Antioxidant and co-antioxidan activity of vitamin $\mathrm{C}$. The effect of vitamin $\mathrm{C}$, either alone or in the presence of vitamin $\mathrm{E}$ or a water-soluble vitamin $\mathrm{E}$ analogue, upon the peroxidation of aqueous multi lamellar phospholipid liposomes. Biochim Biophys Acta 835 (2): 298-303. doi:10.1016/0005-2760(85)90285-1

Durmaz, H., Sevgiler, Y., Uner, N., 2006. Tissue-specific antioxidative and neurotoxic responses to diazinon in oreochromis niloticus. Pesticide Biochemistry and Physiol 84 (3): 215-226. doi:1016/j.pestbp.2005.07.004

Eisler, R. 1998. Diazinon hazards to fish, wildlife and invertebrates: a synoptic review. Biological report 85 , Washington DC: U.S. Fish and Wildlife service.

Fujii, Y., Asaka S., 1982. Metabolism of diazinon and diazoxon in fish live preparations. Bull Environ Contam Toxicol 29 (4): 455-460. doi:10.1007/BF01605611

Goth, L. 1991. A simple method for determination of serum catalase activity and revision of reference range. Clin Chim Acta 196 (2-3): 143-152. doi:10.1016/0009-8981(91)90067-M

Halliwell, B., Gutteridge, J.M., 1990. The antioxidants of human extracellular fluids. Arch Biochem Biophys 280 (1): 1-8 doi:10.1016/0003-9861(90)90510-6

Hazarika, A., Sarkar, S.N., Hajare, S., Kataria, M., Malik, J.K., 2003. Influence of malathion pretreatment on the toxicity of anilofos in male rats: a biochemical interaction study. Toxicology 185 (1-2): 1-8 doi:10.1016/s0300-483x(02)00574-7

Hillton, J.W., Hodson, P.V., Slinger, S.J., 1980. The requirement and toxicity of selenium in rainbow trout (Salmo gairdneri). J Nutr 110 (12): 2527-2535.

Isik, I., Celik, I., 2008. Acute effects of methyl parathion and diazinon as inducers for oxidative stress on certain biomarkers in various tissues of rainbow trout (Oncorhynchus mykiss). Pesticide Biochemistry and Physiology 92 (1): 38-42. doi:10.1016/j.pestbp.2008.06.001

Jarvinen, A. W., Tanner, D.K., 1982. Toxicity of selected controlled release and corresponding unformulated technical grade pesticides to the fathead minnow Pimephales promelas. Environ Pollut 27 (3): 179-195. doi:10.1016/01471(82)90024-1

Kadry, S.M., Marzouk, M.S., Amer, A.F., Hanna, M.I., Azmy, A.H., Hamed H.S., 2012. Vitamin $E$ as antioxidant in female african catfish (Clarias gariepinus) exposed to chronic toxicity of atrazine. Egyption Journal Aquatic Biology and Fisheries 16 (2): 83-98 doi:10.1016/s0013-9351 (02)0006-2

Karaoz, E., Gultekin, F., Akdogan, M., Oncu, M., Gokcimen, A., 2002. Protective role of melatonin and a combination of vitamin $C$ and $E$ on lung toxicity induced by chlorpyrifos-ethyl in rats. Exp Toxicol Pathol 54 (2): 97 108. doi:10.1078/0940-2993-00236

Keizer, J., D’Agostino, G., Nagel, R., Volpe, T., Gnemi, P., Vittozzi. L., 1995 Enzymological differences of AchE and diazinon hepatic metabolism correlation of in vitro data with the selective toxicity of diazinon to fish species. Sci Total Environ 171 (1-3): 213-220. doi:10.1016/0049-9697(95)04687-0

Koprucu, S.S., Koprucu, K., Ural, M.S., Ispir, U., Pala, M., 2006. Acute toxicity of organophosphorous pesticide diazinon and its effects on behavior and some hematological parameters of fingerling European catfish (Silurus glanis L.). Pesticide Biochemistry and Physiology 86 (2): 99-105. doi:10.1016/j.pestbp.2006.02.00

Koracevic, D., Koracevic, G., Djordjevic, V., Andrejevic, S., Cosic, V., 2001. Method for the measurement of antioxidant activity in human fluids. $J$ Clin Pathol 54 (5): 356-361. doi:10.1136/jcp.54.5.356

Ledwozyw, A., Michalak, J., Stepien, A.K., Adziolka. A., 1986. The relationship between plasma triglycerides, total lipids and lipid peroxidation products during huma atherosclerosis. Clin Chim Acta 155 (3): 275-284. doi:10.1016/0009-8981(86)90247-0

Mahfouz, R., Sharma, R., Sharma, D., Sabanegh, E., Agarwal, A., 2009. Diagnostic value of the total antioxidant capacity (TAC) in human seminal plasma. Fertil Steril 91 (3): 805-811. doi:10.1016/j.fertnstert.2008.01.022

Marklund, S., Marklund, G., 1974. Involvement of the superoxyde anion radical in the auto oxidation of pyrogallol and a convenient assay for superoxyde dismutase. Eur J Biochem 47 (3): 469-474 doi:10.1111/j.1432-1033.1974.tb03714.x

McCord, J.M., Fridovich, I., 1969. Superoxide dismutase: an enzymic function for erythrocuprein. J Biol Chem 244 (22): 6049-6055. doi:10.1074/jbc.244.22.6049

Miller, N.J., Rice-Evans, C., Davies, M.J., Gopinathan, V., Milner, A., 1993. A novel method for measuring antioxidant capacity and its application to monitoring the antioxidant status in premature neonates. Clin Sci 84 (4): 407-412. doi:10.1042/cs0840407

Monteiro, D.A., Almeida, J.A.D., Rantin, F.T. Kalinin, A.L., 2006. Oxidative stress biomarkers in the freshwater characid fish, Brycon cephalus, exposed to organophosphorus insecticide Folisuper 600 (methyl parathion). Comp Biochem Physiol C Toxicol Pharmacol 143 (2): 141-149. doi:10/1016 j.cbpc.2006.01.004

Moreau, R., Dabrowski, K., Czesny, S., Chila, F., 1999. VitaminC-vitamin E interaction in juvenile lake sturgeon (Acipenser fulvescens), a fish able synthesize ascorbic acid. J Appl Ich-thyol 15 (4-5): 205-257. doi:10.1111/j.1439-0426-1999/tb00245.x

Payne, J.F., Fancey, L.L., Rahimtula, A.D. Porter, E.L., 1987. Review and perspective on the use of mixed-function oxygenase enzymes in biological moitoring. Comp Biochem Physiol C 86 (2): 233-245. doi :10.1016/0742-8413(87)90074-0

Pereira, B., Rosa, L.F., Safi, D.A., Bechara, E.J., Curi, R., 1995. Hormonal regulation of superoxide dismutase, catalase and glutathione peroxidase activities in ratmacrophages. Biochem Pharmacol 50 (12): 2093-2098. doi :10.1016/0006-2952(95)02116-7

Rotruck, J.T., Pope, A.L. Ganther, H.E., Swanson, A.B., Hafeman, D.G. Hoekstra, W.G., 1973. Selenium: biochemical role as a component of glutathione peroxidase. Science 179 (4073): 585-590 doi : $10.1126 /$ science.179.4073.588

Sies, H., Stahl, W., 1995. Vitamins E and C, betacarotene, and other carotenoids as antioxidants. Am J Clin Nutr 62 (6 Suppl): 1315S-1321S. doi:10.1111/j.1749-6632.1992.tb17085.x

Ural, M.S. 2013. Chlorpyrifos-induced changes in oxidant/antioxidant status and haematological parameters of Cyprinus carpio carpio: Ameliorative effect of lycopene. Chemosphere 90 (7): 2059-2064. doi:10.1016/j.chemosphere.2012.12.006

U.S.EPA. 2006. Reregistration Eligibility Decision (RED) for Diazinon." EPA 738-R-04-006, U.S. Environmental Protection Agency, Office of Prevention, Pesticides and Toxic Substances, Office of Pesticide Programs, Washington DC: U.S. Government Printing Office, 1-112.

Valavanidis, A., Vlahogianni, T., Dassenakis, M., Scoullos, M., 2006. Molecular biomarkers of oxidative stress in aquatic organisms in relation to toxic environmental pollutants. Ecotoxicol Environ Saf 64 (2): 178-189. doi:10.1016/j.ecoenv/2005.03.013

Vale, J.A. 1998. Toxicokinetic and toxicodynamic aspects of organophosphorus OP insecticide poisoning. Toxicol Lett 102-103: 649652. doi:10.1016/S0378-4274(98)00277-X

Van der Oost, R., Beyer, J., Vermeulen, N.P.E., 2003. Fish bioaccumulation and biomarkers in environmental risk assessment: a review. Environ 
Toxicol Pharmacol 13 (2): 57-149. doi:10.1016/S1382-6689(02)00126-6

Verlhac, V., Gabaudan, J., 1997. The effect of vitamin C on Fish Health. Basel: Roche Technical Buletin, Hoffmann-La Roche Ltd, Basel, Switzerland, 30 pp.

Verlhac, V., Obach, A., Gabaudan, J., Schüep, W., Hole, R., 1998 ",Immunomodulation by dietary vitamin $C$ and glucan in rainbow trout (Oncorhynchus mykiss). Fish \& Shellfish Immunology 8 (6): 409-424. doi:10.1006/fsim/1998.0148

Virtue, W.A., Clayton, J.W., 1997. Sheep dip chemicals and water pollution. Sci Total Environ 194-195: 207-217. doi:10.1016/s0048-9697(96)05365-x

Watanabe, T., Takeuchi, T., Wada, M., 1981. Dietary lipid levels and atocopherol requirement of carp. Bulletin of The Japanes Socity of Scientific Fisheries 47: 1585-1590. doi:10.2331/suisan.47.1585
Winston, G.W., Di Giulio, R.T., 1991. Prooxidant and antioxidant mechanisms in aquatic organisms. Aquat Toxicol 19 (2): 137-161.

doi:10.1016/s0891-5849(97)00277-3

Xing, H., Li, S., Wong, Z., Gao, X., Xu, S., Wang, X., 2012. Oxidative stress response and histopathological changes due to atrazine and chlorpyrifos exposure in common carp. Pesticide Biochemistry \& Physiology 103 (1): 74-80. doi:10.1016/j.pestbp.2013.03.007

Zama, D., Meraihi, Z., Tebibel, S., Benayssa, W., Benayache, F., Benayache, S., Vlitinck, A.J., 2007. Chlorpyrifos-induced oxidative stress and tissue damage in the liver, kidney, brain and fetus in pregnant rats: the protective role of the butanolic extract of Paronychie argentea L. Indian Pharmacol 39 (3): 145-150. doi:10.4103/0253-7613.33434 